\title{
The Fate of Proximal Junctional Vertebral Fractures after Long-Segment Spinal Fixation : Are There Predictable Radiologic Characteristics for Revision surgery?
}

\author{
Hyun Jun Jang, Jeong Yoon Park, Sung Uk Kuh, ${ }^{1}$ Dong Kyu Chin, ${ }^{1}$ Keun Su Kim, ${ }^{1}$ Yong Eun Cho, Bang Sang Hahn, ${ }^{2}$ \\ Kyung Hyun Kim ${ }^{1}$ \\ Department of Neurosurgery, Gangnam Severance Hospital, Spine and Spinal Cord Institute, Yonsei University College of Medicine, Seoul, Korea \\ Department of Neurosurgery, ${ }^{2}$ the Leon Wiltse Memorial Hospital, Suwon, Korea
}

Objective : To investigate the radiographic characteristics of the uppermost instrumented vertebrae (UIV) and UIV+1 compression fractures that are predictive of revision surgery following long-segment spinal fixation.

Methods : A total 27 patients who presented newly developed compression fracture at UIV, UIV+1 after long segment spinal fixation (minimum 5 vertebral bodies, lowest instrumented vertebra of $L 5$ or distal) were reviewed retrospectively. Patients were divided into two groups according to following management : revisional surgery (group $A, n=13$ ) and conservative care (group $B, n=14)$. Pre- and postoperative images, and images taken shortly before and after the occurrence of fracture were evaluated for radiologic characteristics

Results : Despite similar degrees of surgical correction of deformity, the fate of the two groups with proximal junctional compression fractures differed. Immediately after the fracture, the decrement of adjacent disc height in group A (32.3 $\pm 7.6 \mathrm{~mm}$ to $23.7 \pm 8.4 \mathrm{~mm}, \Delta=8.5 \pm 6.9 \mathrm{~mm}$ ) was greater than group B $(31.0 \pm 13.9 \mathrm{~mm}$ to $30.1 \pm 15.5 \mathrm{~mm}, \Delta=0.9 \pm 2.9 \mathrm{~mm}, p=0.003)$. Pre-operative magnetic resonance imaging indicated that group $A$ patients have a higher grade of disc degeneration adjacent to fractured vertebrae compared to group B (modified Pfirrmann grade, group A : $6.10 \pm 0.99$, group B : $4.08 \pm 0.90, p=0.004$ ). Binary logistic regression analysis indicated that decrement of disc height was the only associated risk factor for future revision surgery (odds ratio, 1.891; 95\% confidence interval, 1.121-3.190; $p=0.017$ ).

Conclusion : Proximal junctional vertebral compression fractures with greater early-stage decrement of adjacent disc height were associated with increased risk of future neurological deterioration and necessity of revision. The condition of adjacent disc degeneration should be considered regarding severity and revision rate of proximal junctional kyphosis/proximal junction failures.

Key Words : Kyphosis · Reoperation · Spinal fusion/adverse effect · Postoperative complications · Fractures, Compression.

- Received : August 13, 2020 •Revised : September 3, 2020 •Accepted : September 7, 2020

- Address for reprints : Kyung Hyun Kim

Department of Neurosurgery, Gangnam Severance Hospital, Spine and Spinal Cord Institute, Yonsei University College of Medicine, 211 Eonju-ro, Gangnam-gu, Seoul 06273, Korea

Tel : +82-2-2019-3390, Fax : +82-2-3461-9229, E-mail : NSKHK@yuhs.ac, ORCID : https://orcid.org/0000-0002-1338-5523

\section{Bang Sang Hahn}

Department of Neurosurgery, the Leon Wiltse Memorial Hospital, 437 Gyeongsu-daero, Paldal-gu, Suwon 16480, Korea

Tel : +82-31-246-6000, Fax : +82-31-223-2322, E-mail : eramthgin17@gmail.com, ORCID : https://orcid.org/0000-0001-9446-8656

This is an Open Access article distributed under the terms of the Creative Commons Attribution Non-Commercial License (http://creativecommons.org/licenses/by-nc/4.0) which permits unrestricted non-commercial use, distribution, and reproduction in any medium, provided the original work is properly cited. 


\section{INTRODUCTION}

As modern spine surgeons obtain a better understanding of sagittal balance, the importance of spinopelvic alignment beyond just simple segmental decompression or fusion is becoming more clear ${ }^{8,25}$. However, a long and rigid spinal fixation is required to simultaneously acquire sufficient neural decompression, spinal stabilization, and sagittal balance. This fixation leads to commonly recognized junctional problems at the transition between fused and mobile motion segments ${ }^{6,11,13,29)}$. Stresses to adjacent segments generate proximal junction failures (PJF), various complications that result in severe pain, and neurologic deterioration that require repetitive revision surgeries and reduce the patient's quality of life ${ }^{17,322}$.

High rates of PJF occur following long lumbar fusions with complications including proximal segment degeneration, instrument failure, adjacent vertebral compression fractures, and adjacent vertebral segment subluxations ${ }^{18,20,28,30)}$. Predicted risk factors for PJF include older age, greater pre-operative sagittal imbalance, larger amounts of required deformity correction, the presence of comorbidity, fusion to the sacrum, lower bone mineral density (BMD) and body mass index (BMI). However, no study has elucidated a single variable that strongly and consistently predicts PJF development ${ }^{1,216,21-24)}$.

Compression fractures of the uppermost instrumented vertebrae (UIV) and UIV+1 (1-level proximal to UIV) are commonly identified problems seen in follow-up image studies of long-segmented spinal fixation for adult spinal deformity ${ }^{12}$. Among these lesions, conservative care and regular observation can treat fractures that are endurably painful, neurologically intact, and radiographically stable in follow-up images. However, revision surgeries are required for unstable fractures with progressive collapse and kyphosis, as well as lesions with neural compression resulting in both neurologic deficit (e.g., paraparesis or paraplegia) and intractable pain. The prognosis of these patients is variable and unpredictable. Therefore, it is important to differentiate these lesions according to the characteristics predictive of poor natural course, allowing for earlier surgical intervention. The purpose of this study was to investigate the specific radiographic characteristics of UIV and UIV+1 compression fractures that are predictive of necessary revision surgery following long-segment spinal fixation.

\section{MATERIALS AND METHODS}

\section{Patient groupings}

This study was approved by the Institutional Review Board of Gangnam Severance Hospital (IRB No. 3-2019-0056). Through a retrospective review of 275 patients who underwent long-segment spinal fixation (minimum of four levels fused, lowest instrumented vertebra of L5 or distal) in our institution from January 2012 to December 2017, a cohort of 30 patients with newly developed fractures at UIV or UIV+1 were identified. Reasons for long-segment spinal fixation included multi-level spondylotic stenosis, iatrogenic flat back, adjacent segment pathology, post-traumatic kyphosis, and both degenerative lumbar scoliosis and kyphosis. Patients were excluded from the cohort if they were less than 18 years-old or had undergone spinal fixation for either acute traumatic, congenital, inflammatory, metabolic spinal disease, or neoplasm of the spinal cord or vertebrae.

Patients were divided into a revision group (group $\mathrm{A}, \mathrm{n}=13$ ) and a conservative care group (group B, $\mathrm{n}=14$ ) based on the treatment strategy following the development of a compression fracture. Patients in group B had no progression of vertebral compression and underwent no revision surgery for at least 24 months after the compression fracture occurred. One patient was excluded from group B due to less than 24 months of follow-up and two patients were excluded from group A due to incomplete or inadequate radiographs. Images taken shortly before and after the operation or occurrence of fracture were evaluated for radiographic characteristics.

\section{Radiographic analysis}

We investigated radiographic characteristics including the fracture pattern, status of adjacent disc degeneration, parameters for sagittal alignment, and amount of surgical correction after the long-segment spinal fixation.

The wedging rate of compressed vertebrae demonstrates the degree of anterior vertebral wall collapse compared to posterior vertebral wall height (Fig. 1A). A higher percentage suggests more severe compression and collapse of the anterior vertebral wall ${ }^{30)}$. The proximal junctional angle (PJA) was measured using the Cobb angle between the cranial endplate of UIV+2 and the caudal endplate of UIV to evaluate the angulation between the fused and non-fused segments. Additionally, we measured the local kyphotic angle to evaluate the angulation 
around the fractured vertebrae itself, defined as the Cobb angle between the cranial endplate of the vertebrae just superior to the collapsed vertebrae and the caudal endplate of the vertebrae just inferior to the collapsed vertebrae (Fig. 1B). In cases of UIV+1 compression, the PJA was identical to the local kyphotic angle. For the quantitative measurement of disc space around the fractured vertebra, we used the following method using plain radiographs in this study. We measured the vertical distance from the anterior margin of the upper and lower adjacent discs of the fractured vertebra, respectively $(a, b)$, the distance between the center portion of the lower margin of the fractured vertebra and the center portion of the upper margin of the lower vertebra (c), distance between the center portion of the upper margin of the fractured vertebra and the center portion of the lower margin of the upper vertebra (d), the vertical length of the posterior margin of the disc above and below the fractured vertebra was measured (e, f), and the sum of measured values $(\mathrm{a}+\mathrm{b}+\mathrm{c}+\mathrm{d}+\mathrm{e}+\mathrm{f})$ was used as "the disc height" (Fig. 1C). Decrement of disc height ( $\Delta$ disc height) was calculated as the disc height measured after fracture subtracted from the disc height measured before fracture. Modified Pfirrmann grades (1-8), proposed by Griffith et al. ${ }^{9)}$ for the degree of disc degeneration around the fractured vertebrae, were evaluated on whole magnetic resonance imaging (MRI) images taken before long-segment spinal fixation.

Radiographic values, including sagittal vertical axis (SVA; C7 plumb line to postero-superior corner of S1), thoracic kyphosis (T5-T12), lumbar lordosis (L1-S1), pelvic parameters (pelvic incidence, pelvic tilt) were measured using lateral standing whole spine X-ray. Also, we evaluated the BMD and BMI of all included patients.

\section{Statistical analysis}

IBM SPSS 23.0 software (IBM Corp., Armonk, NY, USA) was used for statistical analysis. Unpaired Student's t-tests, chi-squared tests, and Fisher's exact tests were used for comparison between two groups. A binary logistic regression model was used for evaluation of risk factor analysis. A p-value less than 0.05 was considered statistically significant. Results are presented as mean \pm standard deviation. Duration between fracture and revision surgery was expressed as a median value (range) because it did not show a normal distribution in Levene's test, to compare these values between the two groups, a non-parametric, Mann-Whitney U test was performed.

\section{RESULTS}

\section{Demographic data}

Among 275 patients who went through long-segment spinal fixation, 27 patients developed UIV or UIV+1 fractures (9.8\%). Thirteen out of these 27 patients (48\%) underwent revision surgery due to neurologic deficit and/or intractable pain (group A). The median interval time to fracture was 2.5 months (range, 1.3-77.6) for group A and 1.9 months (range, 0.5-35.8) for group B, with no significant differences between two groups. The mean duration between fracture and revision surgery for group A was 9.1 \pm 18.1 months (range, 0.23-34), while the mean duration between fracture and last follow-up for group B (non-surgical, conservative care) was 26.0土9.5 months (range, 25-85).

There were no significant differences in the mean age at operation, BMD, BMI, number of fused vertebrae between the
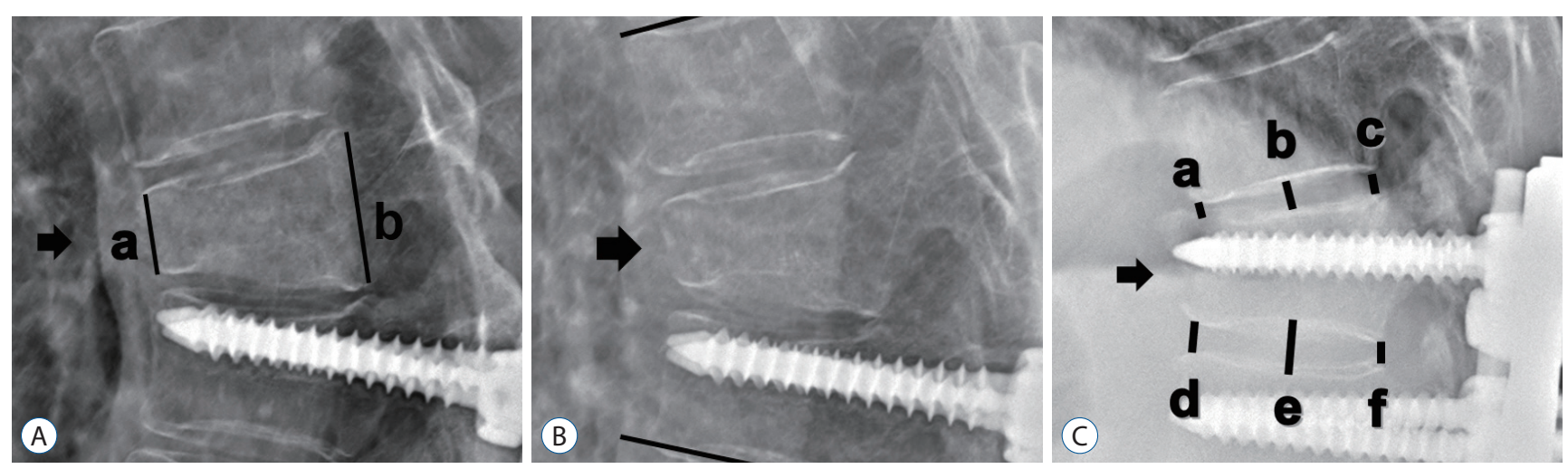

Fig. 1. $A$ : Wedging rate $(\%)=(b-a) / b \times 100$. B : Local kyphotic cobb angle. $C:$ Disc height around fractured vertebrae $=a+b+c+d+e+f$. Arrow indicated fractured vertebrae. $a$ : anterior vertebral wall, $b$ : posterior vertebral wall. 
two groups $(p>0.05)$. Both groups were noted as predominantly female. The upper instrumented vertebrae in group A was $\geq$ T9 $(n=1)$, T10-T12 $(n=9)$, and L1-2 $(n=3)$ compared to $\geq$ T9 $(n=2)$, T10-T12 $(n=8)$, and L1-2 $(n=4)$ in group B. Most spinal fixations were performed to the sacrum or below (sacral alar-iliac), except for two patients in group A and one patient in group B. Excluding two patients (group A) that underwent an index operation with a combined anterior/posterior approach, all patients underwent operation with only a posterior approach (Table 1).

Reasons for long-segment spinal fixation included degenerative lumbar scoliosis $(n=9)$, degenerative lumbar kyphosis $(n=5)$, post-traumatic kyphosis $(n=2)$, iatrogenic flat back $(n=4)$, and adjacent segment disease $(n=7)$. The distribution in the diagnoses between the two groups was not significantly different (Fig. 2).

Table 1. Demographic data for both groups

\begin{tabular}{|c|c|c|c|}
\hline & Group A ( $n=13)$ & Group B $(n=14)$ & $p$-value \\
\hline Age at op (years) & $73.3 \pm 5.3(65-83)$ & $72.0 \pm 4.5(66-82)$ & 0.383 \\
\hline Sex, M:F & $1: 12$ & $2: 12$ & \\
\hline Total follow-up duration (months) & $44.5 \pm 29.6(26-117)$ & $38.9 \pm 15.5(25-85)$ & 0.297 \\
\hline Time to fracture (months) & $2.5(1.3-77.6)$ & $1.9(0.5-35.8)$ & $0.392^{*}$ \\
\hline $\mathrm{BMI}\left(\mathrm{kg} / \mathrm{m}^{2}\right)$ & $21.4 \pm 1.7$ & $23.5 \pm 1.1$ & 0.537 \\
\hline BMD (T-score) & $-2.17 \pm 0.9$ & $-1.97 \pm 0.8$ & 0.117 \\
\hline Fused vertebrae (count) & $7.3 \pm 1.6$ & $7.7 \pm 2.2$ & 0.711 \\
\hline \multicolumn{4}{|l|}{ UIV } \\
\hline$\geq \mathrm{T} 9$ & 1 & 2 & \\
\hline $\mathrm{T} 10-\mathrm{T} 12$ & 9 & 8 & \\
\hline L1-2 & 3 & 4 & \\
\hline Fixation including sacrum & $11 / 13$ & $13 / 14$ & \\
\hline Combined anterior/posterior approach & $2 / 13$ & $0 / 14$ & \\
\hline
\end{tabular}

Values are presented as mean \pm standard deviation (range) or median (range). * Tested by Mann-Whitney U test. op : operation, M : male, F : female, BMI : body mass index, BMD : bone mineral density, UIV : uppermost instrumented vertebrae
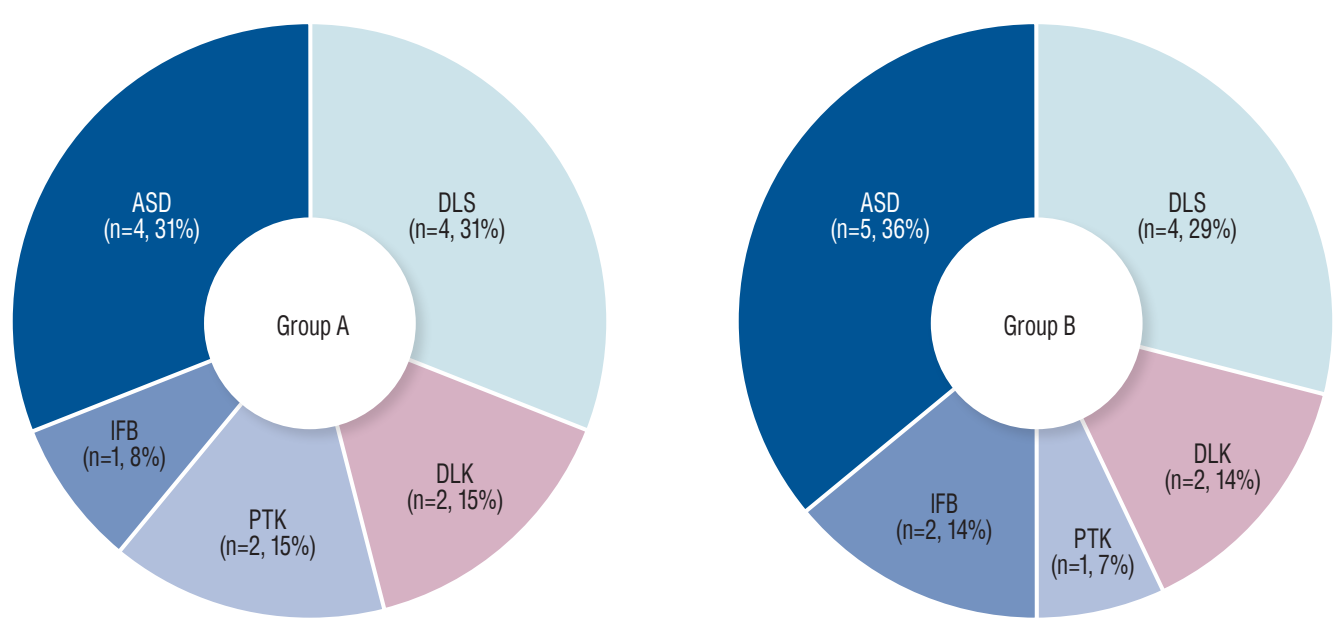

Fig. 2. Pre-operative diagnoses for long-segment spinal fixation. There was no significant difference in the distribution of pre-operative diagnoses between the two groups. Group A : revision surgery, group B : conservative care. ASD : adjacent segment disease, DLS : degenerative lumbar scoliosis, IFB : iatrogenic flat back, PTK : post-traumatic kyphosis, DLK : degenerative lumbar kyphosis. 
Pre- and post-operative sagittal alignment and correction quantity between the two groups

Upon comparing pre- and immediate post-operative radiographs (within 2 weeks), both groups showed SVA correction after long-segment spinal fixation (group A, 92.9 $\pm 57.5 \mathrm{~mm}$ to $39.1 \pm 30.7 \mathrm{~mm}, \triangle \mathrm{SVA}=53.7 \pm 73.8 \mathrm{~mm}$; group $\mathrm{B}, 97.3 \pm 61.6 \mathrm{~mm}$ to $41.8 \pm 26.3 \mathrm{~mm}, \triangle \mathrm{SVA}=55.5 \pm 72.1 \mathrm{~mm}$ ) without significant differences between groups ( $p>0.05)$. After long-segment spinal fixation, both groups showed improvement of PI-LL mismatch (group A, 34.5 \pm 22.0 to $14.2 \pm 13.0, \Delta \mathrm{PI}-\mathrm{LL}=20.2 \pm 18.5$; group $\mathrm{B}, 38.0 \pm 24.1$ to $15.5 \pm 14.7, \Delta \mathrm{PI}-\mathrm{LL}=22.8 \pm 13.2$ ), and decrement of pelvic tilt (group A, $31.9 \pm 9.1^{\circ}$ to $26.6 \pm 5.3^{\circ}$; group $\mathrm{B}, 32.7 \pm 11.0^{\circ}$ to $27.5 \pm 4.4^{\circ}$ ), but there were no statistically significant differences between the two groups (Fig. 3).

\section{Fracture pattern and the pre-operative status of disc degeneration at the index level}

Wedging rate of compressed vertebral body, local kyphotic angle, PJA, and SVA increased in both groups shortly after the occurrence of fracture, with no significant differences between groups (Table 2). Immediately after the fracture, the decrement of adjacent disc height in group A $(32.3 \pm 7.6 \mathrm{~mm}$ to $23.7 \pm 8.4 \mathrm{~mm}, \Delta=8.5 \pm 6.9 \mathrm{~mm})$ was greater than group B (31.0 $\pm 13.9 \mathrm{~mm}$ to $30.1 \pm 15.5 \mathrm{~mm}, \Delta=0.9 \pm 2.9 \mathrm{~mm}, p=0.003)$. Preoperative MRI indicated that group A patients have a higher grade of disc degeneration adjacent to fractured vertebrae compared to group B (modified Pfirrmann grade, group A : $6.10 \pm 0.99$, group B : $4.08 \pm 0.90, p=0.004)$. Binary logistic regression analysis by backward selection steps indicated that $1 \mathrm{~mm}$ decrease in change of the disc height just before and after the occurrence of UIV or UIV+1 fracture, there was 1.89 higher odds of future revision surgery (odds ratio, 1.891; 95\% confidence interval, 1.121-3.190; $p=0.017$; Table 3).

\section{Two different fates of groups and related image findings}

Ten patients in group A (76\%) presented weaknesses of their lower extremities before revision, including three patients who
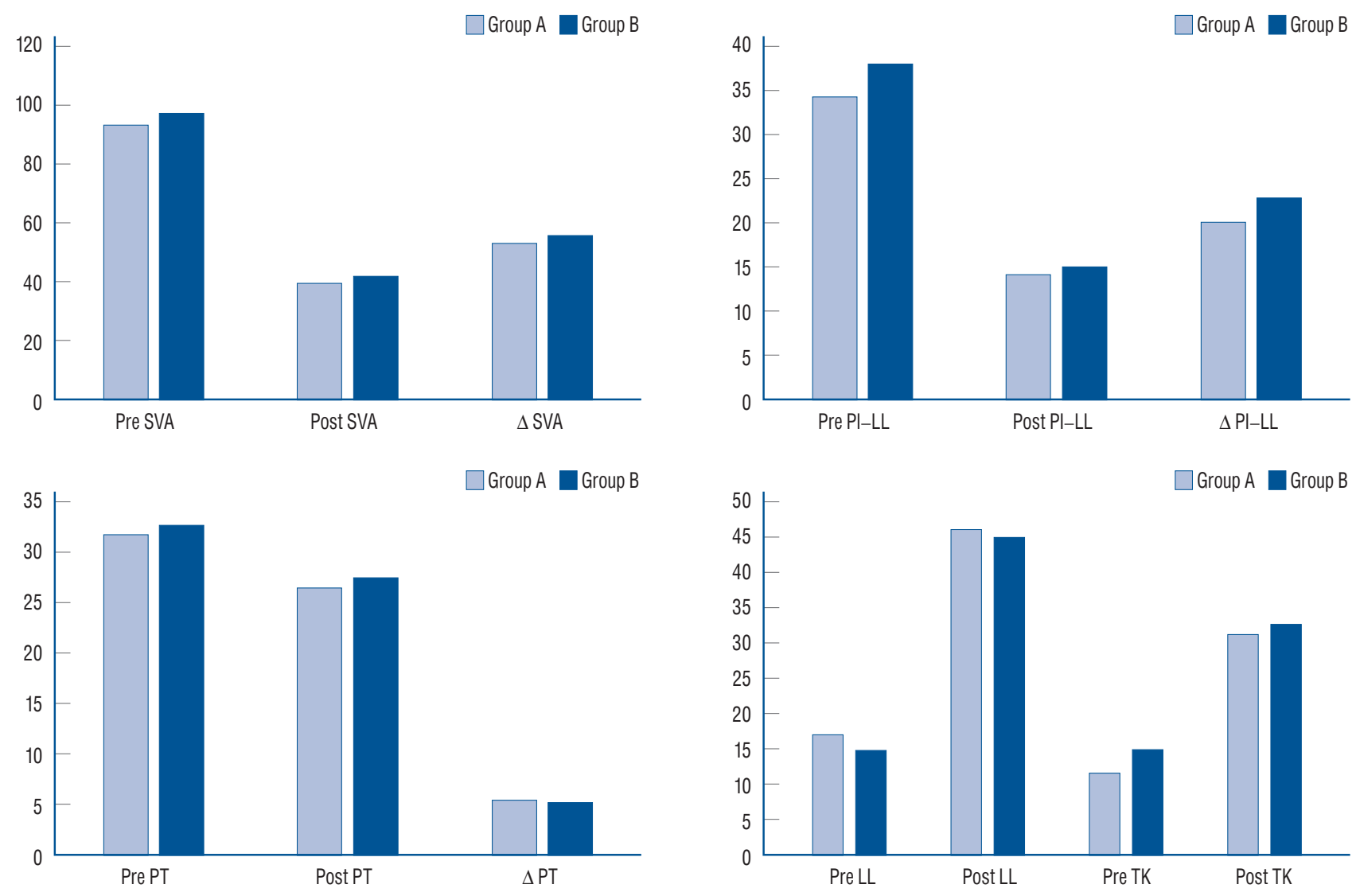

Fig. 3. The amount of surgical correction in both groups analyzed by sagittal parameters measured before (pre-) and after (post-) the long-segment spinal fixation. SVA : sagittal vertical axis, PI : pelvic incidence, LL : lumbar lordosis, PT : pelvic tilt, TK : thoracic kyphosis. 
Table 2. Comparison of parameters just before and after the occurrence of UIV or UIV+1 fracture in both groups

\begin{tabular}{lccc}
\hline & Group A & Group B & p-value \\
\hline Wedging rate $(\%)$ & $8.6 \rightarrow 37.7$ & $11.1 \rightarrow 32.9$ & 0.126 \\
Local kyphosis $\left(^{\circ}\right)$ & $4.3 \rightarrow 23.5$ & $5.6 \rightarrow 21.5$ & 0.213 \\
PJA $\left(^{\circ}\right)$ & $5.1 \rightarrow 23.1$ & $4.2 \rightarrow 21.8$ & 0.270 \\
Sagittal vertical axis $(\mathrm{mm})$ & $40.4 \pm 34.9 \rightarrow 48.7 \pm 42.2$ & $42.7 \pm 27.5 \rightarrow 50.9 \pm 37.7$ & 0.351 \\
Disc height $(\mathrm{mm})$ & $32.3 \pm 7.6 \rightarrow 23.7 \pm 8.4$ & $31.0 \pm 13.9 \rightarrow 30.1 \pm 15.5$ & 0.189 \\
$\triangle$ Disc height $(\mathrm{mm})$ & $8.5 \pm 6.9$ & $0.9 \pm 2.9$ & $0.003^{*}$ \\
Pfirrmann grade (pre-operation) & $6.10 \pm 0.99$ & $4.08 \pm 0.90$ & $0.004^{*}$ \\
\hline
\end{tabular}

Values are presented as before $\rightarrow$ after. *Statistically significant between groups. UIV : uppermost instrumented vertebrae, PJA : proximal junctional angle

Table 3. Binary logistic regression analysis for the evaluation of risk factor for reoperation

\begin{tabular}{lccc}
\hline Variable & $\boldsymbol{p}$-value & Exp (ß) (OR) & 95\% Cl for Exp (B) \\
\hline$\triangle$ Wedging rate $(\%)$ & 0.893 & 0.972 & $0.637-1.483$ \\
$\triangle$ Local kyphosis $\left(^{\circ}\right)$ & 0.344 & 0.895 & $0.710-1.127$ \\
$\triangle \mathrm{PJA}\left({ }^{\circ}\right)$ & 0.517 & 0.907 & $0.675-1.219$ \\
$\triangle \mathrm{SVA}(\mathrm{mm})$ & 0.416 & 0.957 & $0.086-1.064$ \\
$\triangle$ Disc height $(\mathrm{mm})$ & $0.017^{*}$ & 1.891 & $1.121-3.190$ \\
Pfirrmann grade (pre-operative) & 0.180 & 1.689 & $0.785-3.635$ \\
\hline
\end{tabular}

*Statistically significant. Delta $(\Delta)$ values indicate the differences between the two values. Index event : UIV or UIV+1 fracture. OR : odds ratio, Cl : confidence interval, PJA : proximal junctional angle, SVA : sagittal vertical axis, UIV : uppermost instrumented vertebrae

progressed to paraplegic status requiring urgent surgical management. MRI findings just before reoperation showed that compression of the thoracic spinal cord was induced anteriorly by collapsed and herniated discs and posteriorly by buckling of hypertrophied ligament flavum (Fig. 4). The other three patients (23\%) in group A were neurologically intact, but underwent revision surgery due to intractable back or leg pain. There were no neurologic deteriorations in group B patients (Fig. 5).

\section{DISCUSSION}

Despite numerous efforts to avoid it, spine surgeons often face proximal junctional fractures following long segment spinal fixation, and it is important to decide whether to perform a revision surgery or to observe with conservative cares. The proximal junctional kyphosis (PJK) classification and severity scale provided by Hart and the International Spine Study Group $^{12)}$ is well known for reflecting clinical and functional outcomes and predicting the revision rate of $\mathrm{PJK} / \mathrm{PJF}^{19)}$. This system consists of six categorized evaluations (neurologic deficit, focal pain, instrumentation problem, change in kyphosis/ posterior ligamentous complex integrity, UIV/UIV+1 fracture, level of UIV), and higher score is related to revision surgery. However, the condition of intervertebral disc is not considered in this system. To the best of our knowledge, no previous studies have precisely assessed the effect of degeneration of adjacent discs on PJFs and the revision rate. Although Yagi et al. ${ }^{33)}$ mentioned "disc or ligamentous failure" when classifying and estimating severity of PJK/PJF, an association between discs and bony failure was not described. Additionally, no studies investigating the risk factor of revision at the early stage of PJF (no instrumental problems, small PJK angles, or neurologically intact) have been identified.

Several radiologic and technical studies have been carried out to reduce PJK, and among them, prophylactic vertebroplasty is one of the techniques that are often applied ${ }^{3,7)}$. Han et al. ${ }^{10)}$ reported that prophylactic vertebroplasty does not prevent PJK, PJF, and proximal junctional fracture, but could 

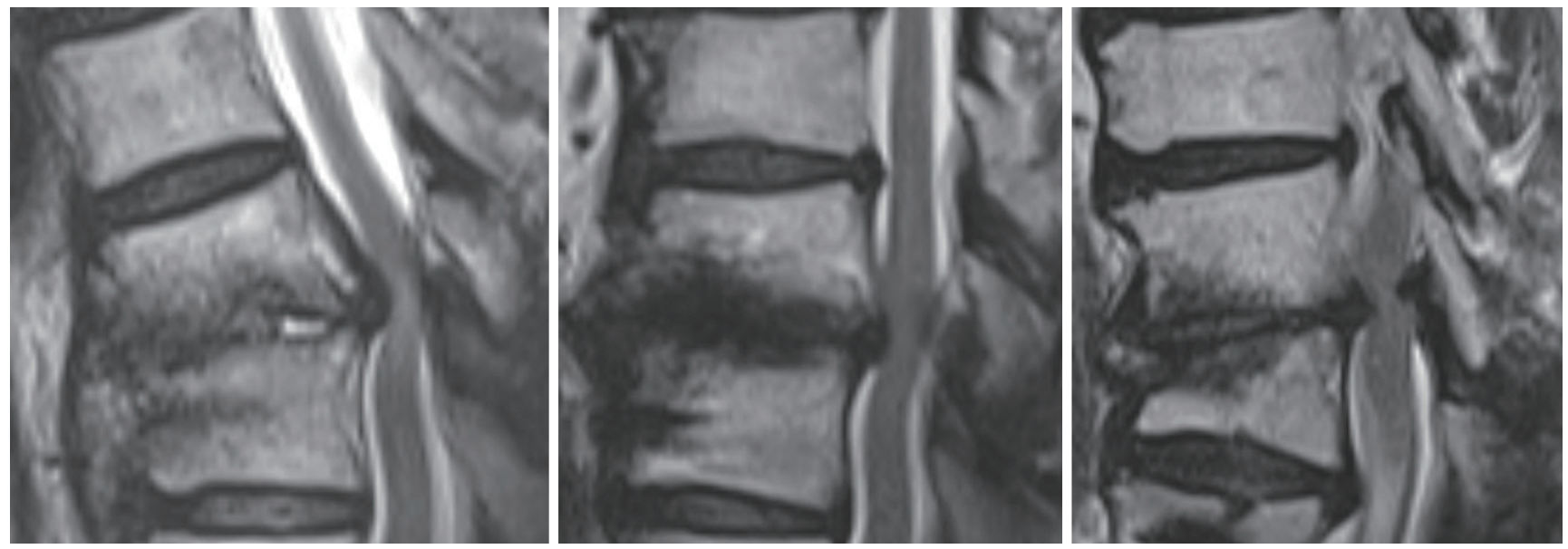

Fig. 4. Pre-revision MRI images of three different patients in group A. Spinal cords were compressed anteriorly by herniated discs and posteriorly by buckling of hypertrophied ligament flavum. MRI : magnetic resonance imaging.
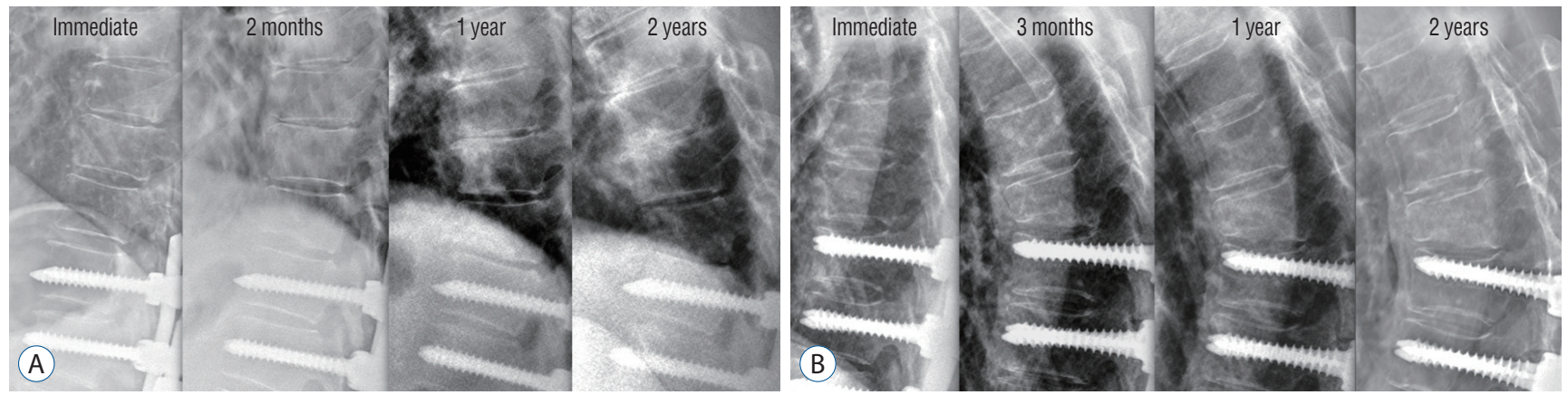

Fig. 5. A : A 64-year-old women with degenerative lumbar scoliosis in group A was initially managed with spinal fixation from T11 to S2 ala-iliac. Two months after the long-segment fixation, a T10 (UIV+1) compression fracture occurred and progressed gradually. After 2 years, revision surgery was performed when the patient complained of weaknesses in both legs. Note that disc space narrowed at the early stage ( 2 months) in spite of relatively mild compression of vertebrae. B : A 72-year-old women with degenerative lumbar scoliosis in group B was initially managed with spinal fixation from T9 to S2 ala-iliac. Three months after the long-segment fixation, a T8 (UIV+1) compression fracture occurred, but remained stable during the 2 years of follow-up. Conservative care was enough for this patient. Note that vertebral wedging and kyphotic angle immediately increased at the time of fracture (3 months), but disc height was preserved relative to disc height in Fig. 4A. UIV : uppermost instrumented vertebrae.

play a positive role in delaying their progression and reduces the reoperation rate. Wui et al. ${ }^{31)}$ reported that the bicortical screw purchase of UIV could rather be a risk factor for UIV compression fracture.

The results of this study indicate that significantly higher rates of revision occur in proximal junctional compression fractures with higher pre-operative adjacent disc degeneration and larger decrement of disc height following the fracture. And the decrement of disc height was found to be the risk factor of revision. Despite similar degrees of surgical correction of deformity, the fate of the two groups with proximal junctional vertebral compression fractures differed. According to our study, it was presumed that proximal junctional fractures adjacent to pre-operatively unhealthy discs appear to collapse more easily at the early stage due to a lower capability of absorbing the axial loading. Although there is a debate in the association between disc degeneration and vertebral fracture, there is a study that severe disc degeneration makes it vulnerable to the forward bending movement, causing more loading on the anterior vertebral body in cadaveric lumbar motion segment ${ }^{26)}$. Some clinical studies have shown that vertebral fractures are more prone in patients with disc degeneration ${ }^{5,27)}$. As fractures become more dysfunctional, the collapse of discs and fractured vertebra progress gradually. Decreased intervertebral height compresses the spinal cord anteriorly by a herniated disc and posteriorly by buckled ligament flavum; the col- 
lapse ends with a neurologic deficit and requires reoperation. The relatively healthy discs in group B may have absorbed adjacent loading more effectively than group A, thus maintaining disc height and preventing further collapse of fractured vertebrae.

Contrary to our expectations that wedging rate, local kyphotic angle, PJA, SVA would be higher in group A, there were no significant differences in these values between the two groups at the early stage of fracture, although these parameters increased at the time of reoperation in group A. Hart et al. ${ }^{11)}$ found that the extent of PJA and SVA influenced the decision to perform revision surgery after PJF. However, SVA and PJA in their study represented "each patient's worst respective measure during the 1-year follow-up period" according to their annotation. On the other hand, SVA and PJA on the images 'immediately after the fractures' in our study were not associated with revision, although these parameters could have significance at the late stage in group A. This information could mean that SVA and PJA at the 'early stage of fracture' cannot be used as a predictive factor for progression and necessity of revision. At the same time, surgeons should be aware that the patient's prognosis may worsen even with mild compression and junctional kyphosis at the early stage of fracture.

In group $\mathrm{A}$, excluding three patients who underwent revision surgery due to severe back or leg pain, the majority of patients $(76 \%)$ presented neurologic deficits, such as paraparesis and paraplegia, gradually after the occurrence of UIV or UIV+1 fractures; some of these patients had permanent deficits even after surgical intervention. Therefore, patients with PJF, especially when there are signs predictive of further collapse and progression, require tight bracing, careful movement in daily life, strong education, and a warning of a possible neurologic deficit from their physician. Furthermore, a shorter term for clinical and radiographical follow-up may be beneficial for these patients.

In our study, we considered no progression of compression during at least 24 months of follow-up to be a stable compression fracture. However, as Hyun et al. ${ }^{14,15)}$ stated in their review article, the incidence of PJK and PJF varies according to the study population and the period of follow-up. Additionally, Daniels et al. ${ }^{4)}$ revealed that major complications and reoperations after surgery for adult spinal deformity primarily happens after 3 months, but can also happen after 12 months, demonstrating bimodal peaks. It is expected that as the follow-up period increases, the total incidence of PJF and reoperation will increase due to aging, degeneration of vertebral structures, comorbidity, traumatic events, and declined BMD among other factors. Group B patients in our study should to be examined in the future for the possibility of sudden progression of compression fractures. Further studies with longer follow-up duration are necessary.

Its retrospective nature and small patient groups limit this study. The small number of sample size and the heterogeneity of surgery level may have influenced the study results. Studies with a larger cohort and biomechanical evaluations are required to clearly ascertain and develop a method of responding to the effect of disc degeneration on the development, progression, and revision rate of PJF.

\section{CONCLUSION}

In this study, proximal junctional vertebral compression fractures with greater early-stage decrement of adjacent disc height were associated with increased risk of future neurological deterioration and necessity of revision. The condition of adjacent disc degeneration should be considered regarding severity and revision rate of PJK/PJF.

\section{CONFLICTS OF INTEREST}

No potential conflict of interest relevant to this article was reported.

\section{INFORMED CONSENT}

This type of study does not require informed consent.

\section{AUTHOR CONTRIBUTIONS}

\author{
Conceptualization : BSH, KHK \\ Data curation : DKC, KSK, YEJ \\ Formal analysis : BSH, KHK \\ Funding acquisition : HJJ, KHK
}


Methodology : JYP, SUK

Project administration : HJJ, BSH

Visualization : $\mathrm{BSH}, \mathrm{KHK}$

Writing - original draft : $\mathrm{HJJ}, \mathrm{BSH}$

Writing - review \& editing : HJJ, KHK

\section{ORCID}

Hyun Jun Jang https://orcid.org/0000-0001-6063-3510

Jeong Yoon Park https:/orcid.org/0000-0002-3728-7784

Sung Uk Kuh https:/orcid.org/0000-0003-2566-3209

Dong Kyu Chin https://orcid.org/0000-0002-9835-9294

Keun Su Kim https:/orcid.org/0000-0002-3384-5638

Yong Eun Cho https://orcid.org/0000-0001-9815-2720

Bang Sang Hahn https://orcid.org/0000-0001-9446-8656

Kyung Hyun Kim https:/orcid.org/0000-0002-1338-5523

\section{- Acknowledgements}

This work was supported by the Korea Medical Device Development Fund grant funded by the Korea government (the Ministry of Science and ICT, the Ministry of Trade, Industry and Energy, the Ministry of Health \& Welfare, the Ministry of Food and Drug Safety) (Project Number : 202014X47).

\section{References}

1. Bridwell KH, Lenke LG, Cho SK, Pahys JM, Zebala LP, Dorward IG, et al. : Proximal junctional kyphosis in primary adult deformity surgery: evaluation of 20 degrees as a critical angle. Neurosurgery 72 : 899-906, 2013

2. Cammarata M, Aubin CÉ, Wang X, Mac-Thiong JM : Biomechanical risk factors for proximal junctional kyphosis: a detailed numerical analysis of surgical instrumentation variables. Spine (Phila Pa 1976) 39 : E500E507, 2014

3. Choi HY, Hyun SJ, Kim KJ, Jahng TA, Kim HJ : Radiographic and clinical outcomes following pedicle subtraction osteotomy : minimum 2-year follow-up data. J Korean Neurosurg Soc 63 : 99-107, 2020

4. Daniels AH, Bess S, Line B, Eltorai AEM, Reid DBC, Lafage V, et al. : Peak timing for complications after adult spinal deformity surgery. World neurosurg 115 : e509-e515, 2018

5. Estublier C, Chapurlat R, Szulc P : Older men with severe disc degeneration have more incident vertebral fractures-the prospective MINOS cohort study. Rheumatology (Oxford) 56 : 37-45, 2017
6. Ghiselli G, Wang JC, Bhatia NN, Hsu WK, Dawson EG : Adjacent segment degeneration in the lumbar spine. J Bone Joint Surg Am 86 : 1497-1503, 2004

7. Glassman SD, Coseo MP, Carreon LY : Sagittal balance is more than just alignment: why PJK remains an unresolved problem. Scoliosis Spinal Disord $11: 1,2016$

8. Glattes RC, Bridwell KH, Lenke LG, Kim YJ, Rinella A, Edwards C 2nd: Proximal junctional kyphosis in adult spinal deformity following long instrumented posterior spinal fusion: incidence, outcomes, and risk factor analysis. Spine (Phila Pa 1976) 30 : 1643-1649, 2005

9. Griffith JF, Wang YX, Antonio GE, Choi KC, Yu A, Ahuja AT, et al. : Modified Pfirrmann grading system for lumbar intervertebral disc degeneration. Spine (Phila Pa 1976) 32 : E708-E712, 2007

10. Han S, Hyun SJ, Kim KJ, Jahng TA, Jeon SI, Wui SH, et al. : Effect of vertebroplasty at the upper instrumented vertebra and upper instrumented vertebra +1 for prevention of proximal junctional failure in adult spinal deformity surgery: a comparative matched-cohort study. World Neurosurg 124 : e436-e444, 2019

11. Hart R, McCarthy I, O'brien M, Bess S, Line B, Adjei OB, et al. : Identification of decision criteria for revision surgery among patients with proximal junctional failure after surgical treatment of spinal deformity. Spine (Phila Pa 1976) 38 : E1223-E1227, 2013

12. Hart RA, Rastegar F, Contag A, Kane M, Daniels A, Klineberg E, et al. : Inter- and intra-rater reliability of the hart-issg proximal junctional failure severity scale. Spine (Phila Pa 1976) 43 : E461-E467, 2018

13. Hilibrand $A S$, Robbins $M$ : Adjacent segment degeneration and adjacent segment disease: the consequences of spinal fusion? Spine J 4(6 Suppl) : 190S-194S, 2004

14. Hyun SJ, Lee BH, Park JH, Kim KJ, Jahng TA, Kim HJ : Proximal junctional kyphosis and proximal junctional failure following adult spinal deformity surgery. Korean J Spine 14 : 126-132, 2017

15. Hyun SJ, Rhim SC, Kim YJ, Kim YB : A mid-term follow-up result of spinopelvic fixation using iliac screws for lumbosacral fusion. J Korean Neurosurg Soc 48 : 347-353, 2010

16. Kim HJ, Bridwell KH, Lenke LG, Park MS, Song KS, Piyaskulkaew C, et al. : Patients with proximal junctional kyphosis requiring revision surgery have higher postoperative lumbar lordosis and larger sagittal balance corrections. Spine (Phila Pa 1976) 39 : E576-E580, 2014.

17. Kim YJ, Bridwell KH, Lenke LG, Glattes CR, Rhim S, Cheh G : Proximal junctional kyphosis in adult spinal deformity after segmental posterior spinal instrumentation and fusion: minimum five-year follow-up. Spine (Phila Pa 1976) 33 : 2179-2184, 2008

18. Kim YJ, Bridwell KH, Lenke LG, Rhim S, Cheh G : Sagittal thoracic decompensation following long adult lumbar spinal instrumentation and fusion to L5 or S1: causes, prevalence, and risk factor analysis. Spine (Phila Pa 1976) 31 : 2359-2366, 2006

19. Lau D, Funao H, Clark AJ, Nicholls F, Smith J, Bess S, et al. : The clinical correlation of the Hart-ISSG Proximal Junctional Kyphosis Severity Scale with health-related quality-of-life outcomes and need for revision surgery. Spine (Phila Pa 1976) 41 : 213-223, 2016

20. Lewis SJ, Abbas H, Chua S, Bacon S, Bronstein Y, Goldstein S, et al. : 
Upper instrumented vertebral fractures in long lumbar fusions: what are the associated risk factors? Spine (Phila Pa 1976) 37 : 1407-1414, 2012

21. Maruo K, Ha Y, Inoue S, Samuel S, Okada E, Hu SS, et al. : Predictive factors for proximal junctional kyphosis in long fusions to the sacrum in adult spinal deformity. Spine (Phila Pa 1976) 38 : E1469-E1476, 2013

22. Nguyen NL, Kong CY, Hart RA : Proximal junctional kyphosis and failurediagnosis, prevention, and treatment. Curr Rev Musculoskelet Med 9 : 299-308, 2016

23. O'Leary PT, Bridwell KH, Lenke LG, Good CR, Pichelmann MA, Buchowski JM, et al. : Risk factors and outcomes for catastrophic failures at the top of long pedicle screw constructs: a matched cohort analysis performed at a single center. Spine (Phila Pa 1976) 34 : 2134-2139, 2009

24. Park SJ, Lee CS, Chung SS, Lee JY, Kang SS, Park SH : Different risk factors of proximal junctional kyphosis and proximal junctional failure following long instrumented fusion to the sacrum for adult spinal deformity: survivorship analysis of 160 patients. Neurosurgery $80: 279$ 286, 2017

25. Phan K, Nazareth A, Hussain AK, Dmytriw AA, Nambiar M, Nguyen D, et al. : Relationship between sagittal balance and adjacent segment disease in surgical treatment of degenerative lumbar spine disease: metaanalysis and implications for choice of fusion technique. Eur Spine J 27 : 1981-1991, 2018

26. Pollintine $P$, Dolan $P$, Tobias JH, Adams MA : Intervertebral disc degeneration can lead to "stress-shielding" of the anterior vertebral body: a cause of osteoporotic vertebral fracture? Spine (Phila Pa 1976) 29 :
774-782, 2004

27. Shirado O, Kaneda K, Tadano S, Ishikawa H, McAfee PC, Warden KE : Influence of disc degeneration on mechanism of thoracolumbar burst fractures. Spine (Phila Pa 1976) 17 : 286-292, 1992

28. Smith MW, Annis P, Lawrence BD, Daubs MD, Brodke DS : Acute proximal junctional failure in patients with preoperative sagittal imbalance. Spine J 15 : 2142-2148, 2015

29. Soh J, Lee JC, Shin BJ : Analysis of risk factors for adjacent segment degeneration occurring more than 5 years after fusion with pedicle screw fixation for degenerative lumbar spine. Asian Spine $J 7$ : 273-281, 2013

30. Watanabe K, Lenke LG, Bridwell KH, Kim YJ, Koester L, Hensley M : Proximal junctional vertebral fracture in adults after spinal deformity surgery using pedicle screw constructs: analysis of morphological features. Spine (Phila Pa 1976) 35 : 138-145, 2010

31. Wui SH, Hyun SJ, Kang B, Kim KJ, Jahng TA, Kim HJ : Bicortical screw purchase at upper instrumented vertebra (UIV) can cause UIV fracture after adult spinal deformity surgery: a finite element analysis study. Neurospine $17:$ 377-383, 2020

32. Yagi $M$, King $A B$, Boachie-Adjei 0 : Incidence, risk factors, and natural course of proximal junctional kyphosis: surgical outcomes review of adult idiopathic scoliosis. Minimum 5 years of follow-up. Spine (Phila Pa 1976) 37 : 1479-1489, 2012

33. Yagi M, Rahm M, Gaines R, Maziad A, Ross T, Kim HJ, et al. : Characterization and surgical outcomes of proximal junctional failure in surgically treated patients with adult spinal deformity. Spine (Phila Pa 1976) 39 : E607-E614, 2014 